\title{
Meatproteome of 2, 4-D degradation analysis between agro chemical contaminated soils
}

\author{
Karthika. D, King Solomon. E, Rajesh Kannan. V* \\ Rhizosphere Biology Laboratory, Department of Microbiology, Bharathidasan University, Tiruchirappalli-620024 \\ *Corresponding author E-mail: uvrajesh@gmail.com
}

\begin{abstract}
Bioremediation is a process to remove pollutants from soil by employing microorganism. One of the most major herbicide that contaminates soil is 2, 4-Dichlorophenoxyacetic acid. There are several molecular and proteomics analyses have been used to find out the biological interaction, but met proteomics is an ideal tool to study the biological interactions between soil and microorganisms in the ecosystem. The present study has focused on to identify the removal of 2, 4-D by soil microbes. The 2, 4-D degrading bacteria from these soil samples were produced chlorocatechol deoxygenates. Here, 2, 4-D enriched soil samples were studied through experimentally with HPLC and met proteome of soil were analyzed using SDS-PAGE. Based on the study it has revealed that sample 1 and 3 completely degraded but sample 2 was degraded only $80 \%$ on significantly. The preliminary reports of the soil bioremediation study have been provided a paradigm for met proteomic research on soil biology.
\end{abstract}

Keywords: Bioremediation, metaproteomics, herbicides, pollutants, SDS-PAGE.

\section{Introduction}

Metaproteomics is a promised method to identify the function and role of soil microorganisms in bioremediation. It possible to execute large-scale proteome analyses of species whose genome sequences have been published [1]. The information obtained from the soil metaproteome could be useful for studying soil-mediated bioremediation processes. Hence, the significance metaproteomics resides the identification of proteins and microbial species are involved in soil processes, such as indicators of soil quality and functionality. Now-a-days agrochemicals are used in large scale for increasing the crops yield and soil fertility. Among the agrochemicals 2, 4-D usage is high in all types of cultivation lands. Also 2, 4-D (2, 4- dichlorophenoxyacetic acid) is degraded by microbes in the soil, naturally which is occurred by specific enzyme through microbes. 2, 4-D has potent leach to the soil and contaminate groundwater [2]. 2, 4-D has been used as a chemical model to study the evolution and diversity of catabolic genes in the degradation of anthropogenic environmental contaminants. Although 2, 4-D is readily degraded as a carbon source by various environmental microorganisms [3]. The efficiency of the degradation of 2, 4-D by microorganism can be monitored by using HPLC, since this allows determining the amount of herbicides metabolites in the samples [4]. Physico-chemical properties of soil are the essential for microbial growth. Soil proteins acts as functional biomarker and can be studied to 1-DE (SDSPAGE) and 2- DE. The diversity of environmental microbial communities while addressing functional aspects more directly can be studied using metagenomic/meta-transcriptome approach. The suitability of the extraction method for the functional soil metaproteome in soil samples that had been incubated with 2, 4-D and inoculated with degrading capable bacteria can be studied using SDS PAGE and 2-DE. Thus, it is possible way to target proteins for metaproteome analysis. The availability of SDS-PAGE and the development of mass spectroscopy have enabled the metaproteome to be studied such complex ecosystems like water and soils, in which several microbial communities interact and have diverse functions [5].

\section{Materials and methods}

Soil samples were collected from $5 \mathrm{~cm}$ depth in chemical fertilizer contaminated, paddy field in Thanjavur (sample1 \& 2) and Tiruchirappalli (sample 3). The collected specimen soils were filled in three individual columns. Treated and pretreated soil samples were analyzed for physico-chemical characteristics. The samples containing column were percolated with minimal medium, containing $2 \mathrm{mM} 2$, and $4-\mathrm{D}$ at a flow rate of $4 \mathrm{ml} \mathrm{h}-1$ until the end of the experiment 
after 25 days for enrichment in minimal medium. Extracted medium were analyzed for HPLC (phenomenex- 5u c18 column) and acetonitrile as mobile phase and detected at $225 \mathrm{~nm}$ [4]. The protein was separated by one-dimensional electrophoresis SDSPAGE [6].

\section{Results and discussion}

Metaproteomic analysis of microorganisms in soil has been hampered by the lack of effective methods for extracting proteins directly from soil in a manner that is compatible with proteomic techniques [7]. Metaproteome approach was one of the major tools used to analyze total protein present in soil and groundwater environments. 2, 4-D is degraded by metaproteome of microbial communities during metabolism in the environment were analyzed and the retention time of respective peak was compared with the standard 2, 4- D degradation. The metaproteome estimated with Lowry's after ammonium sulphate precipitation and it further was analysed by SDS- PAGE (Fig. 1).

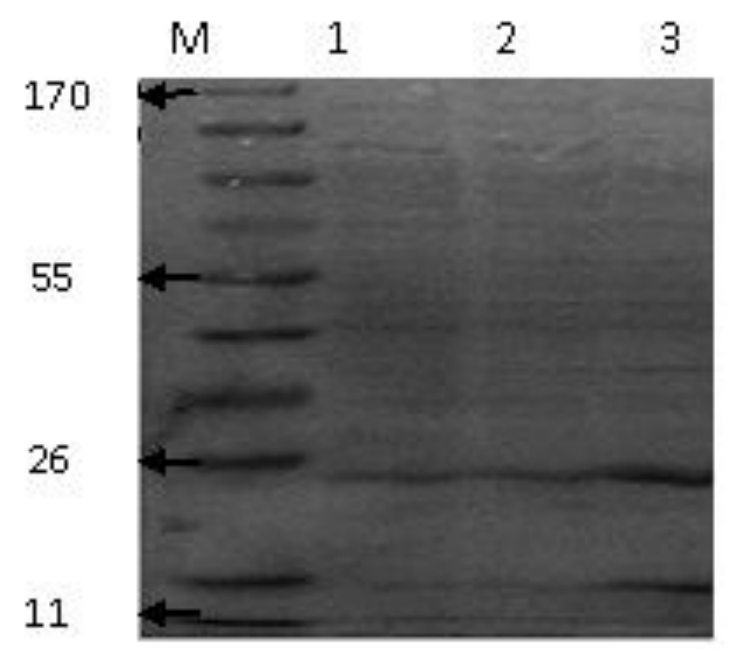

Fig. 1: One-dimensional gel electrophoresis in polyacrylamide: lane m: protein marker (10-170k Da) lane 1: sample 1, lane 2: sample 2, lane 3: sample 3 .

The degradation of soil 2, 4-D is by the microbial community. Hence, the minimal medium was added in soil samples during the incubation period, in which some minerals were also added. These additional minerals change the soil nature and their nutrients level. This will promote the growth of soil microbial consortia. However, this minimal medium does not contain any carbon source, therefore 2; 4-D was added in the minimal medium as a carbon source for soil microbes. For three different treated soil samples and there is no significant changes in the $\mathrm{pH}$ value. The sample 2 was showed high in EC (1.41dsm-1), Nitrogen (98\%) compare than other two soils and Potassium was high in sample1 $(227.5 \mathrm{mg} / \mathrm{kg})$. The soil nutrients promote the growth of soil microbes; hence it proved that there is a change in the physico-chemical properties of natural soil, after the treatment with 2, 4-D. In soil environment, the physico-chemical parameters play an important role to find out the level of chemical nature which would be interlink with microbial communities survival $[8,9]$. The interactive effects were analyzed through the soil $\mathrm{pH}$, soil fertility in the agriculture environment [10].

Nutrient plates contain numerous bacterial colonies and SDA (Sabouraud Dextrose agar) contain very few fungal colonies. This microbial consortium was able to degrade the 2, 4-D.

treated soil sample than pre-treated soil were indicated that the 2,4-D was not completely degrade in sample2 compare than sample1 and sample 3 because it was already contaminated with some chemicals or it may take some long time to degrade in the high toxic persistence soils. 2, 4-D in the three soils was found to be mineralized by the microorganism present in the soil because mineralization will be reduced or inhibit the availability of chemicals. 2, 4-D is a quite constant chemical with a half- life period from 20 to 200 days. The use of 2, 4-D had severely affects for both agricultural and environment system. So to reduce the impacts of 2, 4-D over soil was investigated, here through the metaprotemic degradation. However, the metaproteomics is science to identify total proteins in soil and thus, it could provide a strong support to study the structure and function of microbial communities in soil. Future efforts we directed towards the confirmation of our metaproteomic approach emphasis on: (a) 2-Dimensional Electrophoresis (b) MALDITOF to recognize the depth of the degradation. 


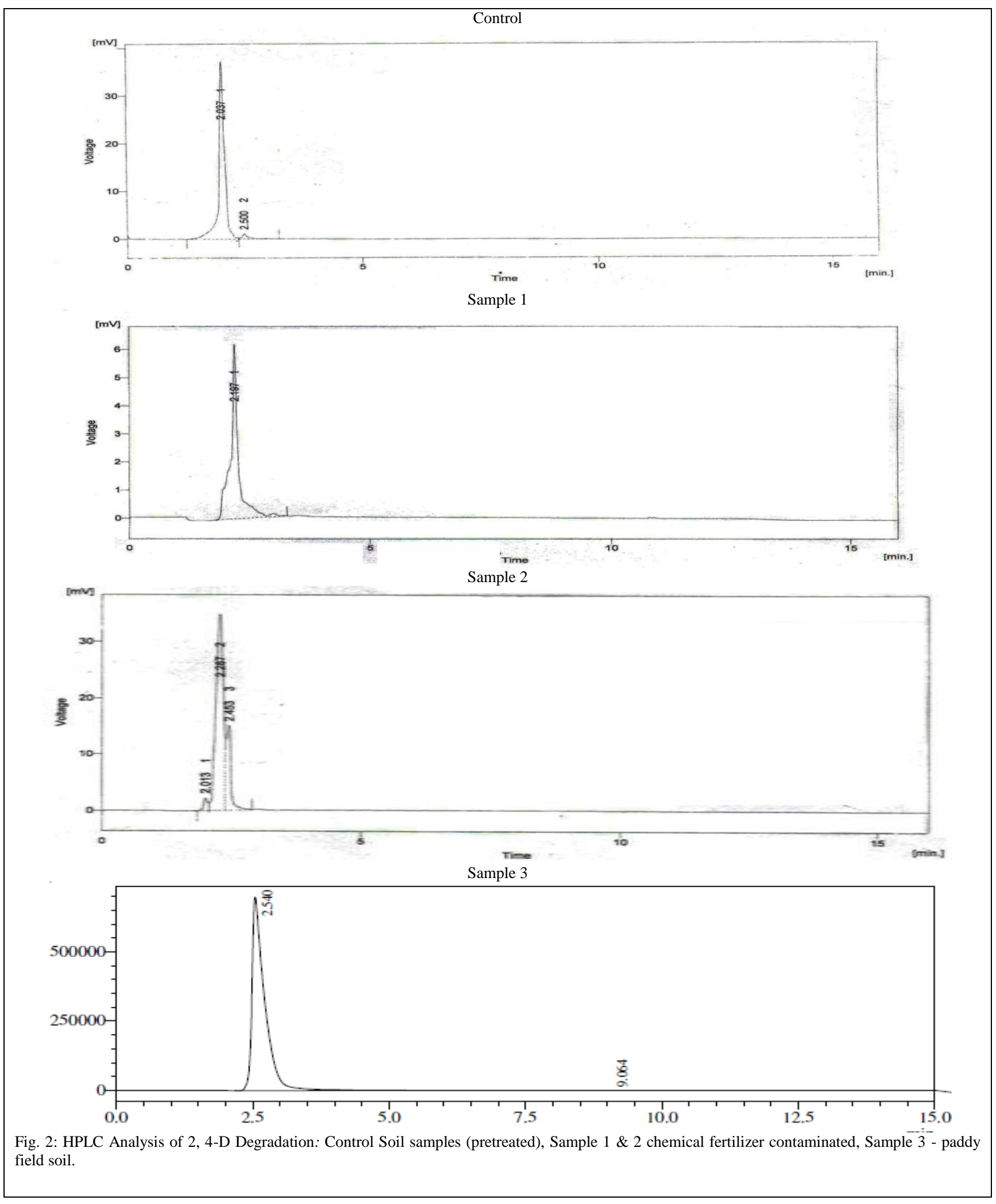




\section{Conclusion}

This plating proved the presence of microbes in both treated and untreated soil samples. Protein estimation was performed for three pre-treated soil and post treated soil, sample 2 contains high amount of protein $(983.8 \mathrm{Hg})$ after treatment than other soil samples. All together high amount of protein was obtained than the pre-treated soils. This result proved the production of enzyme as high amount in soil samples after the incubation with 2, 4-D. It has been previously reported that $1 \mathrm{~g}$ of soil contain at least $0.58 \mathrm{mg}$ of protein, which is 2 to 10 times more than the typical protein content of natural soils [11]. Further it was analyzed with HPLC to measure the quantity of 2, 4-D herbicide in the medium with UV detector. The sample 2 contain $20 \%$ of 2, 4-D and remaining $80 \%$ of 2, 4-D was degraded in the sample.Hence 2, 4-D has been slowly degraded than others contaminated soils (Fig. 2). Both 2, 4-D and 2, 4Dichlorophenol (DCP) were analyzed by HPLC [12]. There are few salts like $0.1 \mathrm{M} \mathrm{NaoH}$, ammonium sulphate and ammonium chloride were used to extract and to precipitate the protein [13]. A gram of soil should contain at least $0.58 \mathrm{mg}$ of protein, 2, 4-D degraders, was more than 2 to 10 times higher than the typical protein content of natural soils [11]. In this investigation the relationship and interface between soil characteristic, total protein, microbial communities and degradation were analyzed by protein estimation, SDS-PAGE, HPLC and presence of high protein amount in

\section{Acknowledgements}

The authors would like to express heartfelt thanks to the Rhizosphere biology group, Department of Microbiology, Bharathidasan University, Tiruchirappalli, Tamil Nadu, and India for providing lab facilities.

\section{References}

[1] Ishino, Y., Okada, H., Ikeuchi. M and Taniguchi, H. (2007). Mass spectrometry-based prokaryote gene annotation. Proteomics, 7, $4053-4065$.

[2] Tonso N. L., Matheson V.G., Holben W.E., (1995). Polyphasic characterization of a suite of bacterial isolates capable of degrading 2, 4 -D. Microbial Ecol 30: 1-22

[3] Lee T,H., Kurata S., Nakatsu C.,H, Kamagata Y., (2005). Molecular Analysis of Bacterial community Based on 16s rDNA Functional Genes in Activated Sludge Enriched with 2, 4- Dichlorophenoxyacetic acid under Different cultural conditions. Microbio. Ecol 49:151-162.

[4] Amarante junior O, P., Santos T, C., R, Nunes G, S. (2003). Concise revision of methods for determination of the herbicide dichlorophenoxyacetic acid (2, 4-D). Quim nova 26: 223-229.

[5] Bastida F., J. L. Moreno., C. Nicola' S., T. Hernandez and Garcia C. (2009). Soil metaproteomics: a review of an emerging environmental science. Significance, methodology and perspectives. European Journal of Soil Science, 60, 845-859.

[6] Ogunseitan, O.A. (2006). Soil proteomics: extraction and analysis of proteins from soil. In: Nucleic Acids and Proteins in Soil, Series:Soil Biology, Volume 8 (eds P. Nannipieri \& K. Smalla), 95-115

[7] Carla M.R Lacerda and Kenneth F. Reardon., (2009). Environmental proteomics: Applications of proteome profiling in environmental microbiology and biotechnology. Briefings in Functional Genomics and Proteomics. 1-13.

[8] Ernst, W (1976). Physiological and biochemical aspects of metal tolerance. In Effects of air pollutants on plants .Cambridge University Press, $115-133$.

[9] Tapan Adhikari., Ajay Kumar., M. V. Singh., and A. Subba Rao (2010) Phytoaccumulation of Lead by Selected Wetland Plant Species. Communications in Soil Science and Plant Analysis, 41:2623-2632

[10] Maruthi Sankar. R. G.,V. Subramanian, K. L., Sharma., P. K. Mishra ., S. Jyothimani .,K. Bhaskar., D. Jawahar., M. Rajeswari., T. Taghavan., G. Ravindra Chary., A. Renuka Devi., K. A. Gopinath., B. Venkateswarlu and J. Kusuma Grace (2012) Communications in Soil Science and Plant Analysis Volume 43, Issue 5.

[11] Vance ED., Brookes PC and Jenkinson DS (1987).An extraction method for measuring soil microbial biomass C. Soil Biol. Biochem. 19, 703-707.

[12] Vroumsia T., Steiman R., Seigle-Murandi F., Benoit-Guyod J.L. (2005) .Fungal bioconversion of 2,4-dichlorophenoxyacetic acid (2,4-D) and 2,4 dichlorophenol (2,4- DCP). Chemosphere, 60(10): 1471-1480.

[13] Dirk Benndorf. Gerd U Balcke., Hauke Harmo and Martin Von Bergen., (2007). Functional metaproteome analysis of protein extract from contaminated soil and groundwater 1: 224-234. 